EPiC Series in Engineering
Volume 3, 2018, Pages 1022-1029
HIC 2018. 13th International
Conference on Hydroinformatics

\title{
Enhancing automated water level control at navigable waterways by high-resolution weather predictions
}

\author{
Julia Kasper ${ }^{1}$, Georg Pranner ${ }^{1}$, Franz Simons ${ }^{1}$, Michael Denhard ${ }^{2}$ and \\ Carsten Thorenz ${ }^{1}$ \\ ${ }^{1}$ Federal Waterways Engineering and Research Institute, Karlsruhe, Germany \\ ${ }^{2}$ Deutscher Wetterdienst, Offenbach am Main, Germany \\ julia.kasper@baw.de
}

\begin{abstract}
Heavy rainfall can cause large variations in the water level of navigable waterways when a lot of urban runoff is generated on sealed surfaces and discharged into the river. Due to climate change, extreme weather events will increase in intensity and frequency demanding a better automated water level control at impounded waterways. Highresolution forecasts of catchment rainfall are intended to serve as input to a rainfallrunoff model. Based on the resulting discharge forecasts, a model predictive feed forward controller calculates the ideal water level and discharge across the barrage. The control system is completed by a PI control loop. In this way water level deviations and discharge peaks resulting from stormwater overflow events can be reduced, which enhances the safety of shipping. Regarding the uncertainties of weather predictions, the consequences of an underestimated or overestimated overflow discharge are investigated.
\end{abstract}

\section{Introduction}

About $3000 \mathrm{~km}$ of the navigable inland waterways in Germany are controlled by barrages in order to enable safe navigation and to use hydroelectric power. Each barrage is equipped with a manual or automated control system that maintains the desired water level by adapting the discharge across the weir and the turbines of the hydropower station. Discharge and water level control at navigable waterways has to fulfil several, in some instances opposing requirements: keeping the water level within a prescribed tolerance range, minimizing discharge fluctuations, releasing flood waters, maximizing the efficiency of hydroelectric power plants as well as reducing mechanical wear of weir gates. 
The automated control systems usually being designed by the Federal Waterways Engineering and Research Institute take into account the current amount of inflow from the upstream barrage, whereas lateral inflows remain unknown until the resulting water level variation reaches the gauge located directly upstream of the barrage [1]. Taking the example of the Hofen reach at the river Neckar, lateral inflow due to combined sewer overflow from the main collector Nesenbach can be up to $130 \mathrm{~m}^{3} / \mathrm{s}$. As the Neckar discharges about $50 \mathrm{~m}^{3} / \mathrm{s}$ at mean flow conditions and about $12 \mathrm{~m}^{3} / \mathrm{s}$ during low water periods, the automated control cannot cope with such enormous discharge variations. In consequence, the water level may exceed the permitted tolerance limit to a large extent, which decreases the safety of shipping [2,3]. Furthermore, discharge peaks can amplify in a chain of barrages [4].

The $\mathrm{R} \& \mathrm{D}$ project "Strategies for automated discharge and water level control at navigable waterways under extreme weather conditions" is part of the BMVI Network of Experts initiated by the Federal Ministry of Transport and Digital Infrastructure (BMVI) in 2016. Seven executive agencies of the BMVI jointly address urgent transport infrastructure problems through innovations in their adaptation to climate change, their environmentally sound design and their reliability [5].

With increasing intensity and frequency of extreme weather events, climate change will have a larger impact on discharge and water level control at navigable waterways. For this reason, the Federal Waterways Engineering and Research Institute is developing a new control strategy which is based on detailed weather forecasting by the German Meteorological Service (Deutscher Wetterdienst) to predict stormwater overflow discharge from urban catchment areas into a river reach [6]. In this paper, three main components are described: weather forecasting, the urban rainfallrunoff model and the automated control system.

\section{Precipitation forecasts}

The German Meteorological Service runs a Numerical Weather Prediction (NWP) system, which consists of a global ensemble with 40 members that contains a nesting area over Europe with $20 \mathrm{~km}$ horizontal resolution [7]. The European nest provides boundary conditions for high-resolution forecasts $(2.2 \mathrm{~km})$ with the COSMO-DE-EPS, an ensemble prediction system over Germany for lead times up to $27 \mathrm{~h}$ every $3 \mathrm{~h}$ [8]. In addition, precipitation measurements from radar with $1 \mathrm{~km}$ resolution are available, which update every $5 \mathrm{~min}$. From these measurements, the German Meteorological Service generates forecasts of precipitation amounts for the next $2 \mathrm{~h}$ in the framework of so-called "nowcasting".

Since nowcasting of precipitation is more skilful in the beginning of the forecast than numerical weather predictions, which is due to spin up problems in the models, we start here using predictions from nowcasting. These precipitation forecasts are aggregated in the relevant catchment areas of the Neckar river around the city of Stuttgart. Forecasting extreme precipitation events is quite difficult and the amounts and locations of the precipitation fields can show large variations.

\section{Rainfall-runoff modelling}

A simple rainfall-runoff model for the sewage system of the main collector Nesenbach in Stuttgart, based on cascades of linear reservoirs, was developed as part of an earlier work at the Federal Waterways Engineering and Research Institute [9]. Given a time series of a rainfall forecast, this model predicts the resulting combined sewer overflow discharge into the Neckar river.

Figure 1 shows a schematic view of the two urban sub-catchment areas represented by the model. The upstream sub-catchment includes a rainwater overflow basin and two rainwater retention basins. 
These are used for temporary storage of the storm "first flush", as it contains heavily polluted water. From the overflow basin in the downstream sub-catchment, the combined sewer overflow is discharged into the Neckar river. The rainfall-runoff model was implemented in the model-based design software Simulink ${ }^{\circledR}$ and the model parameters were determined empirically by estimating the size of the sealed surface in the water catchment, length and slope of the sewage system as well as the flow velocity. The model has two inputs, consisting of the mean rainfall intensity in each subcatchment, and two outputs, consisting of the filling level of the downstream rainwater basin and the overflow discharge into the Neckar river.

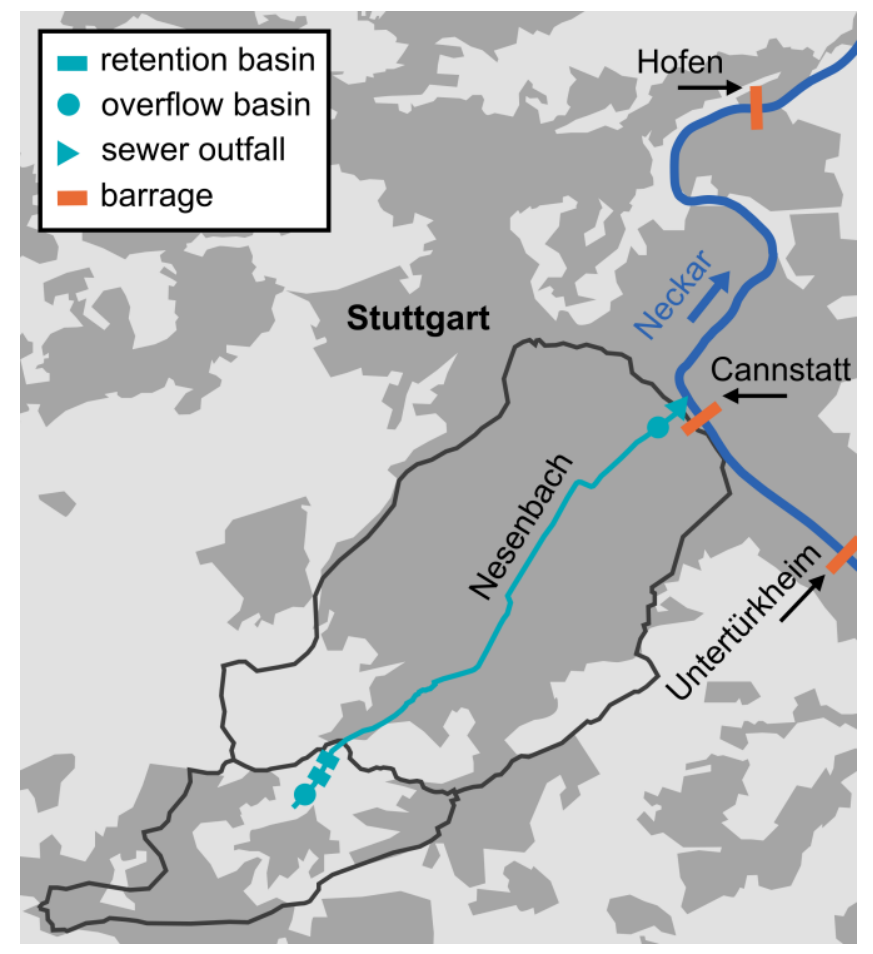

Figure 1: The Neckar river within the densely built-up area (dark grey) of the city of Stuttgart, the barrages Untertürkheim, Cannstatt and Hofen, the two catchment areas of the main sewer Nesenbach, the locations of relevant rainwater basins and the location of the combined sewer outfall

By analysing measurements of combined overflow of the main sewer Nesenbach in Stuttgart, several significant events in 2016 have been identified. For these events, rainfall intensities from historical weather records are fed into the rainfall-runoff model and the resulting overflow discharge into the Neckar river is compared to the measurements. The precipitation data is obtained from the RY product of the German Meteorological Service which consists of quality corrected five-minute radar composite Quantitative Precipitation Estimation (QPE). The model parameters initially determined empirically are calibrated on the basis of these comparisons. This is not an easy task, as the measured data from the sewage system are incomplete and especially the measurements of the overflow discharge are inaccurate due to the long overflow edge.

In Figure 2, the results of the calibrated model are displayed against the measurements for a heavy summer rainfall event that serves as an example. Both filling level and overflow discharge of the rainwater basin, especially the gradients when rising, are well represented by the rainfall-runoff model. For other overflow events captured by the measurements, the discharge is underestimated by 
up to $60 \%$ or overestimated by up to $80 \%$ in the simulation. In order to judge the performance of the rainfall-runoff model, errors in the radar composite QPE as well as in the combined sewer overflow measurements must be taken into account. For this reason, the accuracy of the model is considered to be sufficient.
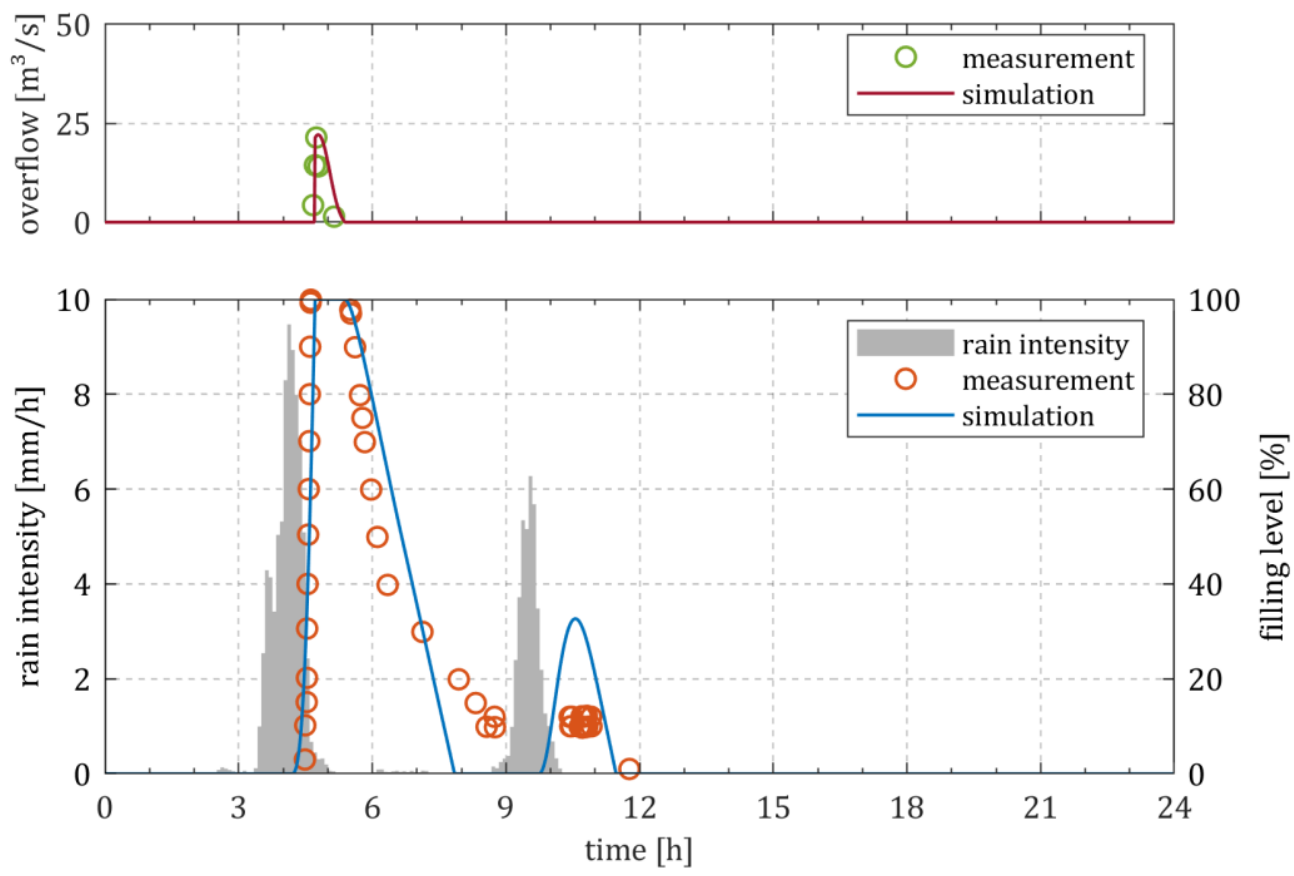

Figure 2: Mean instantaneous rain intensity of both sub-catchments and comparison between simulated and measured filling level of the rainwater overflow basin and overflow discharge into the Neckar river for a heavy summer rainfall event

\section{Automated control system}

The automated control system which is usually applied at navigable waterways in Germany consists of a PI controller and disturbance feed forward compensation (FFC) of upstream inflow variations, using first order low pass filters and an inflow-dependent time delay [1]. As this offers only a limited time interval to react on predicted inflow variations, the present work is based on a model predictive feed forward control (MPFFC) that is currently being developed by the Institute for System Dynamics at the University of Stuttgart [10].

\subsection{Model predictive feed forward control}

The MPFFC replaces the original feed forward component and needs as input the desired water level as well as an inflow prediction, including lateral inflow from urban runoff. The inflow from the upstream barrage is given by distant discharge measurements. The MPFFC contains an internal model of the impounded river section which is built from the linearized 1D Saint-Venant equations. This 
simplified model is calibrated by using optimization techniques, comparing its solution to the solution of an existing non-linear 1D Saint-Venant model.

Figure 3 shows the operating principle of a model predictive control. Given an inflow prediction and assuming unmodified discharge of the barrage, the future water level is calculated for the prediction horizon. In the following step, the discharge trajectory during the control horizon is optimized in order to compensate the predicted inflow and find an ideal water level trajectory. Only the first value of the optimized water level trajectory and the optimized discharge trajectory are used by the control system, serving as set value for the PI controller and as disturbance feed forward compensation, respectively. At each time step, the whole process is repeated so that the MPFFC always takes into account the newest inflow predictions.

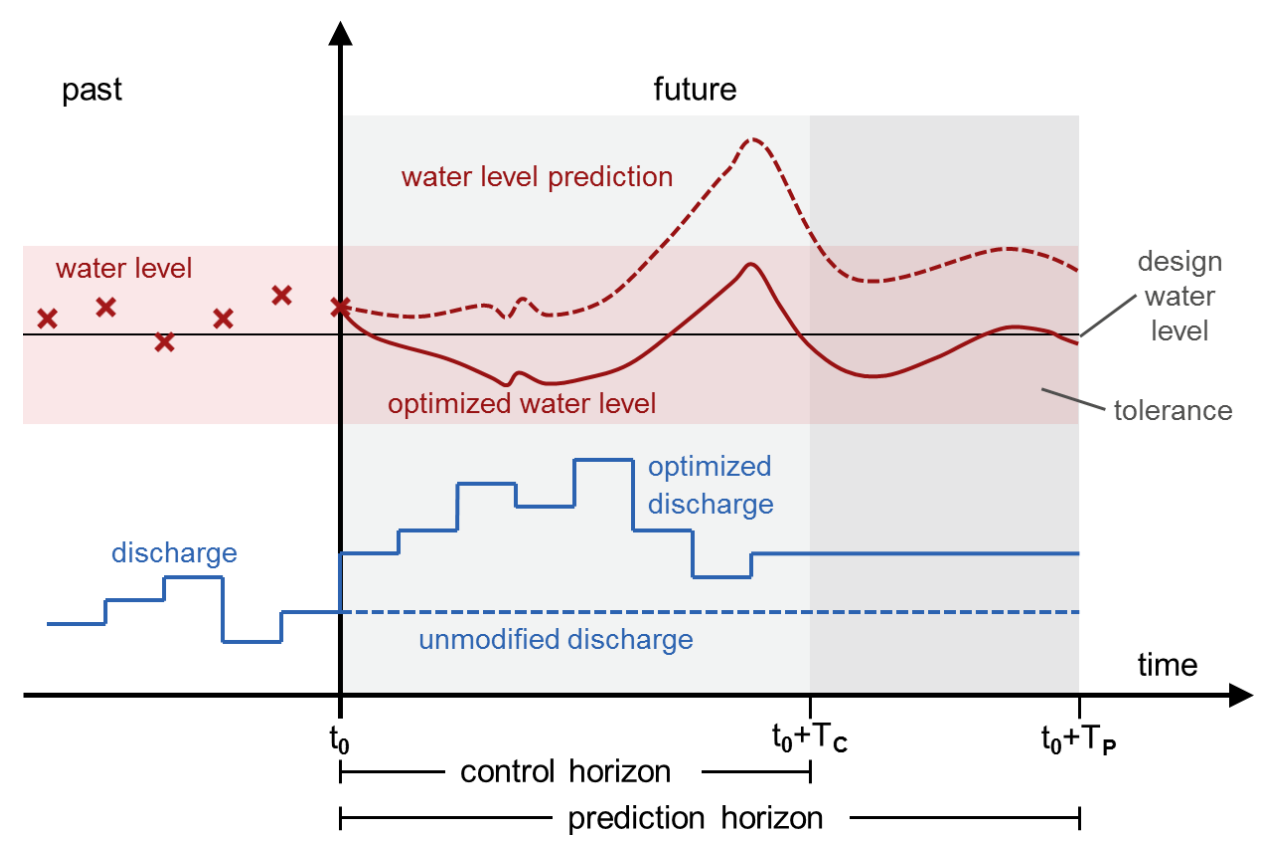

Figure 3: Prediction horizon $T_{P}$ and control horizon $T_{C}$ of a model predictive control at time step $t_{0}$

The PI control loop at the barrage ensures that the set value of the water level is maintained. In this way, errors in discharge predictions are compensated. As shown in [10], the MPFFC avoids violations of the water level deviation limits and considerably reduces discharge peaks.

To investigate the performance of the new control strategy, artificial combined sewer overflow scenarios are generated, based on the regional rainfall frequency analysis of the German Meteorological Service [11] for the two sub-catchment areas mentioned in Section 3. The rainfallrunoff model yields the maximum overflow discharge of $130 \mathrm{~m}^{3} / \mathrm{s}$ for an extreme precipitation event with a return period of 50 years and a duration of $60 \mathrm{~min}$. A non-linear 1D Saint-Venant model is used to simulate the flow behaviour of the impounded river reach Hofen. The discharge of the upstream barrage is set to $35 \mathrm{~m} / \mathrm{s}$, which is between low and mean water. As the combined sewer outfall is located near to the upstream barrage, base flow and overflow discharge are added up to form the total inflow into the river reach. The water level is determined directly upstream of the Hofen barrage, where an upper deviation of $15 \mathrm{~cm}$ from the design water level is permitted.

Without any knowledge of the combined sewer overflow, the originally used control system as well as the model predictive control system produce poor results. With both systems, the tolerance is first exceeded by about $15 \mathrm{~cm}$ upwards, then by about $8 \mathrm{~cm}$ downwards. In addition, the discharge 
peak due to the overflow event is increased by about $16 \%$ for both control systems, causing problems for the downstream impoundments.

If the overflow prediction is taken into account by the control system, the respective behaviour shown in Figure 4 is obtained. As proposed in [12], the control horizon of the MPFFC was reduced from an original value of $T_{C}=3 \mathrm{~h}$ to $T_{C}=2 \mathrm{~h}$ because Hofen is a comparatively short reach with little storage capacity. Both systems maintain the water level more or less perfectly within the tolerance range, but with the original feed forward compensation the inflow wave is increased by about $12 \%$ at the outflow of the reach. In contrast, the MPFFC avoids amplification of inflow peaks even in the case of maximum possible overflow discharge. The small difference between the target water level calculated by the MPFFC and the actual water level shows that the PI controller only needs to compensate for small inaccuracies of the MPFFC's internal linearized model.
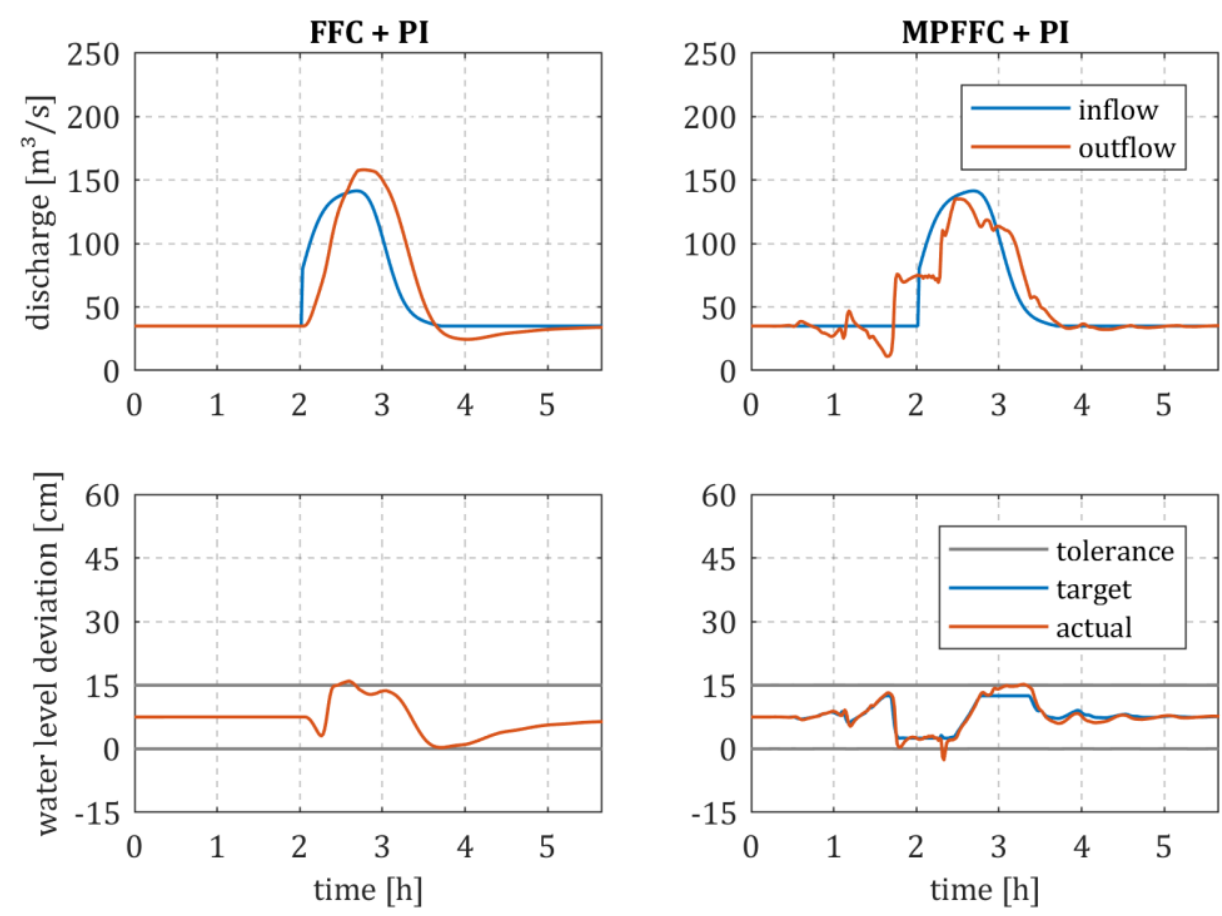

Figure 4: Consequences of an extreme overflow event at the Hofen impoundment using the original feed forward compensation (FFC+PI) and the model predictive feed forward control (MPFFC+PI) with a perfect discharge prediction

\subsection{Uncertainty of overflow discharge forecasts}

In order to investigate the consequences of a combined sewer overflow predicted too high or too low, the MPFFC is supplied with incorrect forecasts for an artificial event with a return period of one year and a duration of $60 \mathrm{~min}$. The resulting overflow discharge of this annual event reaches a maximum value of $37 \mathrm{~m} / \mathrm{s}$ and thus doubles the chosen inflow into the river reach. In Figure 5, the behaviour of the MPFFC system for an underestimating as well as an overestimating prediction is presented. In both situations, the water level is maintained within the tolerance range. Concerning underestimated inflow, the discharge is damped by $8 \%$ compared to the inflow and it shows less fluctuation than for overestimated inflow. In that latter case, the automated control is not able to 
reduce the amplitude of the discharge wave. From these results it can be concluded that combined sewer overflow should better be predicted too low rather than too high when uncertainties of the forecasts are to be taken into account.
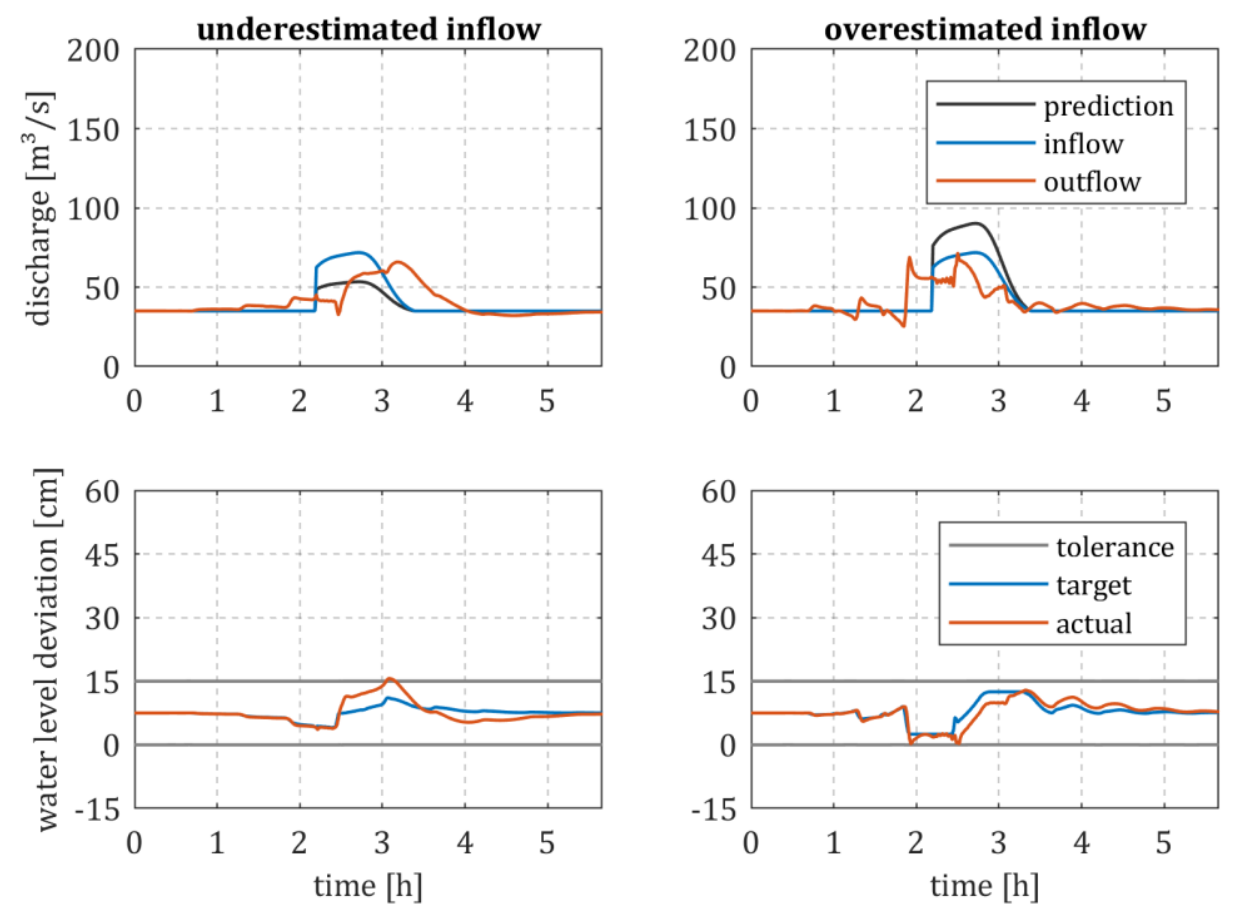

Figure 5: Consequences of an annual overflow event at the Hofen impoundment using the model predictive feed forward controller (MPFFC+PI) with a discharge prediction that underestimates the inflow by $50 \%$ or overestimates it by $50 \%$

\section{Conclusions}

High-resolution nowcasting of observed precipitation fields offers the possibility of incorporating short-term and small-scale discharge forecasts for urban runoff into the automated water level control at navigable waterways. A simplified hydrological model is used to predict combined sewer overflow for the main sewer Nesenbach in the city of Stuttgart, which is discharged into the Neckar river. This urban rainfall-runoff model was calibrated using measured data and provides sufficient accuracy.

Independently of the control strategy applied at the Hofen impoundment, violations of the water level tolerance caused by heavy rainfall events can only be prevented by overflow discharge forecasts. Beyond that, discharge peaks are successfully reduced by the model predictive feed forward control system. From the investigations it can be concluded that an underestimating forecast is preferable to an overestimation from the point of view of the control system.

Future investigations will focus on the implementation of a fully automated process, which will include ensemble forecasts from nowcasting and longer range numerical ensemble predictions to obtain estimations of forecast uncertainty for the combined sewer overflow discharge.

The authors would like to thank the Civil Engineering Office of the city of Stuttgart, Germany for providing data on combined sewer overflow. 


\section{References}

[1] P. Schmitt-Heiderich, Motivation zum FuE-Vorhaben „Optimierungsverfahren für die Parametrisierung von Reglern der automatisierten Abfluss- und Stauzielregelung (ASR)“, in: Automatisierte Abfluss- und Stauzielregelung, BAWMitteilungen Nr. 96, Federal Waterways Engineering and Research Institute, Karlsruhe, 2012, pp. 7-14.

[2] F. Belzner, P. Schmitt-Heiderich, Einfluss urbaner Einzugsgebiete auf die Abfluss- und Stauzielregelung, in: Innovation mit Tradition: Hydraulischer Entwurf und Betrieb von Wasserbauwerken, BAWKolloquium, Federal Waterways Engineering and Research Institute, Karlsruhe, 2012, pp. 93-98.

[3] P. Schmitt-Heiderich, F. Belzner, Verfahren zur Parametrisierung von PI-Reglern einer automatisierten Abfluss- und Stauzielregelung, in: Automatisierte Abfluss- und Stauzielregelung, BAWMitteilungen Nr. 96, Federal Waterways Engineering and Research Institute, Karlsruhe, 2012, pp. 123-133.

[4] M. Gebhardt, S. Wohlfart, Die automatische Regelung einer Stauhaltungskette - Von den Voruntersuchungen bis zur Inbetriebnahme der automatisierten Moselstaustufen, in: Automatisierte Abfluss- und Stauzielregelung, BAWMitteilungen Nr. 96, Federal Waterways Engineering and Research Institute, Karlsruhe, 2012, pp. 135-144.

[5] Federal Ministry of Transport and Digital Infrastructure, BMVI Network of Experts, Berlin, 2017. Available at http://www.bmvi-expertennetzwerk.de/EN.

[6] J. Kasper, F. Simons, F. Belzner, P. Schmitt-Heiderich, Einfluss von Starkregenereignissen auf die Abfluss- und Stauregelung am Beispiel der Neckarstauhaltung Hofen, in: Modellierung aktueller Fragestellungen zur Wassermengenbewirtschaftung an Bundeswasserstraßen, Veranstaltungen 5/2017, Bundesanstalt für Gewässerkunde, Koblenz, 2017, pp. 139-146.

[7] M. Denhard, C. Primo, H. Frank, A. Rhodin, J.T. Ambadan, H. Anlauf, A. Fernandez del Rio, A. Cress, R. Potthast, M. Buchhold, The spread skill properties of the global ICON Ensemble, 2017, in preparation.

[8] C. Gebhardt, S.E. Theis, M. Paulat, Z. Ben Bouallègue, Uncertainties in COSMO-DE precipitation forecasts introduced by model perturbations and variation of lateral boundaries, Atmos. Res. 100 (2011), 168-177.

[9] F. Belzner, Einfluss der Mischwasserentlastung der Stadt Stuttgart bei sommerlichen Starkregen-ereignissen auf die Abfluss- und Stauzielregelung am Neckar, Master's thesis, Karlsruhe University of Applied Sciences, 2011, unpublished.

[10] K.-U. Amann, E. Arnold, O. Sawodny, Online real-time scheduled model predictive feedforward control for impounded river reaches applied to the Moselle river, in: 2016 IEEE International Conference on Automation Science and Engineering (CASE), IEEE, Fort Worth, TX, USA, 2016, pp. 1276-1281.

[11] T. Junghänel, H. Ertel, T. Deutschländer, Bericht zur Revision der koordinierten Starkregenregionalisierung und -auswertung des Deutschen Wetterdienstes in der Version 2010, German Meteorological Service, Department of Hydrometeorology, Offenbach am Main, 2017.

[12] G. Pranner, Anwendung einer modellprädiktiven Vorsteuerung für die Abfluss- und Stauregelung von Wasserstraßen am Beispiel der Neckarstauhaltung Hofen, Bachelor's thesis, Karlsruhe Institute of Technology, 2018, unpublished. 